\title{
ACERCA DE LO HISPÁNICO EN LA UNIVERSIDAD ARGENTINA \\ Reflexiones para un diálogo en la integración
}

\author{
Ada Lattuca \\ Universidad Nacional de Rosario. Argentina
}

La enunciación del tema que nos ocupa tiene sentido en el marco de la recepción hispánica en la institución Universidad. Sin embargo, la instrumentalización esgrimida en diversos ciclos históricos comprende, en su más amplio sentido, la visión del comportamiento asumido por aquella institución en los movimientos políticos que conforman en definitiva la historicidad argentina.

1.-Desde los albores de los primeros gobiernos patrios - 1810 - la historiografía oficial se encargó de demostrar la utilización por sus protagonistas de la denominada "máscara fernandina" para ocultar la profunda raigambre del derecho castellano. En aras a tal postura, las acciones desarrolladas por aquéllos eran una especie de teatralización de la verdadera fidelidad al monarca. Luego, al hilo de tal concepción las causas del movimiento emancipador debían buscarse en la obra de los ideólogos y teorizadores como Rousseau, Montesquieu, las constituciones norteamericana y francesa, las rebeliones precursoras en el continente americano y en una débil referencia, de la doctrina suareciana en la tesis de la retroversión del poder al pueblo ${ }^{1}$.

En líneas generales, continuamos siendo tributarios de la Universidad de corte liberal creada en Buenos Aires, en $1821^{2}$, y tendemos a soslayar el legado de la creada en Córdoba, (1613) por España. Así, también, se suelen hacer referencias, vagas y dispersas a la institución de San Marcos en la ciudad de Lima (1551) que alcanzó un singular prestigio debido a la seriedad de 
sus estudios, la participación activa del estudiantado y su original organización ${ }^{3}$.

2.-El siglo XX, se conmocionó con el movimiento de la Reforma Universitaria producido en 1918, bajo la presidencia del gobierno radical, de corte populista, de Hipólito Yrigoyen, elegido en los primeros sufragios libres del país merced a la aplicación de la ley sancionada por su antecesor en 1912 al implantar el voto secreto, universal y obligatorio, y dar participación parlamentaria a la primera minoría, para canalizar la opinión pública en un bipartidismo de raíz anglo-sajona. La proyección de esta eclosión estudiantil fue enorme. La conmoción en los claustros de las tres universidades nacionales fue, en cierta medida, producto de un proceso dialéctico 4 . El fin de la belle èpoque subrayó la crisis del nacionalismo exacerbado y la ilusión en un progreso indefinido. Cayeron regímenes absolutistas, la revolución rusa excitaba las pasiones juveniles y enconaba la resistencia reaccionaria. "El estado-gendarme cedía paso al estado-social, y un nuevo constitucionalismo colectivista se abría paso en Querétaro y en Weimar"s. La reacción fue dirigida contra el sistema de gobierno imperante por entonces en las universidades argentinas, en particular en la de Córdoba por su fuerte impronta teológica y conservadora. Es en aquella ciudad donde emergió la chispa que provocó y dinamizó la fértil lucha estudiantil en miras a lograr reivindicaciones largamente postergadas y que irradiarán su contenido a vastas regiones del continente como: Perú, Chile, Uruguay, Méjico, Medellín, Bogotá, La Habana, etc. Su Manifiesto Liminar, dirigido por la juventud universitaria de Córdoba "a los hombres libres de Sudamérica", se iniciaba expresando: "Hombres de una República libre, acabamos de romper la última cadena que, en pleno siglo XX, nos ataba a la antigua dominación monárquica y monástica".

A pesar de no compartir la misma naturaleza de problemas, los universitarios del resto de la República se unieron en la cruzada de defenestración hacia las "estructuras clericales y aristocratizantes, por ser resabio de la época colonial". No queremos minimizar el movimiento, que cayó muy pronto en la instrumentalización política, sólo interesa verificar que en los corsi e ricorsi que acompañan a la historia argentina la apelación a las tradiciones hispánicas o su manifiesto rechazo ha obedecido, en gran medida, a la concepción sustentada por los supremos repartidores de turno ${ }^{6}$.

La vasta eclosión reformista - protagonizada por estudiantes y miembros de clase media - que intentó con bastante éxito inicial proceder a la democratización universitaria, proclamó la necesidad de autonomía, asistencia libre, docencia libre, periodicidad de la cátedra, gobierno tripartito, libertad de juramento (en la de Córdoba se juraba por los Santos Evangelios), el 
derecho a la insurrección "contra la tiranía de una secta religiosa y de la estrecha formación dogmática," vio quebrados sus mejores frutos en la década posterior a su estallido. La ausencia de un "anclaje" entre la universidad y el medio fueron debilitando la fuerza de sus postulados y ello se debió, muy probablemente, a los dilemas internos surgidos en la evolución institucional así como a la permanente vocación de ascenso de las clases medias preocupadas por la obtención de sólidas inserciones en la estructura vigente 7 . El primer golpe de Estado presidido por el general Uriburu (1930), contó en sus momentos iniciales con la simpatía y la adhesión de sectores reformistas que aplaudieron la caída del gobierno de Yrigoyen.

Los ciclos de nuestra historia universitaria han acompañado y complementado la escisión de nuestra conciencia jurídica política obstaculizando el diálogo tan esencial en aras a producir el ambiente de cooperación y de convivencia superador de estériles divisiones. Es pertinente destacar que la responsabilidad no se opera, frente a la evolución histórica argentina - deformada por las tendencias liberales y revisionistas a ultranza- sólo desde el ciclo superior. Es cada vez más grave el estado de inconsistencia y casi de total desconocimiento del estudiantado de las escuelas medias, candidatos a ingresar en las aulas universitarias, sobre temas de historia argentina y de indiferencia total hacia el extenso período hispánico ${ }^{8}$.

3.-En América Latina, y en el caso argentino en especial, la universidad no ha llegado a convertirse en un válido agente de transmisión social de un modelo cultural así como de modelos de pensamiento adecuados para

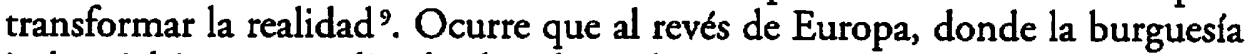
industrial intentó realizarlo, las clases dominantes (Los que Mandan, según una feliz expresión de Imaz) no quisieron, o no les interesó legitimarse como agentes de un modelo de desarrollo adecuado que pudiera captarlo la institución educativa. Por otra parte, el Estado no produjo pautas válidas en las que se asentaría un funcionamiento racional. Así, el devenir universitario se tornó cada vez más fluctuante y procedió a implementar planes coyunturales alejados, por lo común, de su específico quehacer. "Los movimientos universitarios buscaron sea preservarse de los gobiernos mediante la autonomía, sea convertirse en agentes políticos. Tampoco dieron relevancia a la construcción de un modelo cultural o a la creación de modelos de pensamiento alternativos" 10 .

En especial, en el ámbito argentino hallamos una "importación" de modelos de pensamiento moderno a partir de mediados del siglo XIX, que respondió a un intento forzado de las élites dominantes los ilustrados (hacendados, burguesía comercial e intelectuales del espacio bonaerense y de su capital la "ciudad puerto") por conseguir las mecánicas aptas que lo integra- 
rían al civilizado espacio europeo. Todo cuanto no proviniese del Viejo Mundo resultaba salvaje o bárbaro. Los teorizadores de la propuesta de renovación profunda de la historia americana denunciaban constantemente el "exceso de americanismo", para ellos el americanismo auténtico era "...aquél que concibe como sujeto de la historia al patriota liberal, americano y moderno". La revolución de América, dirá Alberdi, fue hecha por el pueblo europeo de origen y de raza, no el pueblo de nacionalidad indígena y salvaje". Cuando finalizó la dominación ibérica en todo el continente americano y se produjo la fascinación hacia los países europeos actores de la revolución industrial, la cultura hispánica por la cual habíamos entrado en la "civilización" fue declarado "barbarie". "El mundo cristiano hispánico quedó relegado, dentro de las líneas más radicales de nuestro pensamiento político y social, a la misma categoría en que había quedado para él, el mundo pagano prehispánico" ${ }^{12}$.

4.-En realidad, los hombres de la denominada Generación del '37 y los posteriores liberales ilustrados no hicieron más que ahondar la ruptura con nuestro sentido de historicidad genuina, reemplazando con otras "invenciones" modernas guiadas con una mixtura de base positivista y pragmatismo norteamericano. El grupo criollo que condujo la revolución emancipadora va a iniciar esta conciencia de ruptura al capitalizar el movimiento y erigirse en estamento dominador que recogieron, con éxito merced a su actividad política y económica, sus herederos en base a un proyecto ideológico que miraba sólo desde el presente que había que modificar hacia la consecución de un futuro cuyo modelo se iba armando, y en la consideración de un pasado perdido, clausurado. Así se gestó una historiografía en la que esos protagonistas creyeron traducir la voz de toda la comunidad, y que será la voz, el discurso, de una realidad desgarrada, escindida en dos porciones. El hecho lo ubica claramente un escritor peruano al definir a una parte como pequena, luminosa y llena de palabras y otra, inmensa, sombría y silenciosa ${ }^{13}$.

La identidad pues de los "supremos repartidores" debía recaer en la aristocracia y no en los republicanos democráticos, sea cual fuere su signo monárquico o republicano. Y tal conformación se da casi en América toda. Al hilo de tal concepción se ahonda la división entre lo civilizado lo europeo, y salvaje lo americano. No llama la atención, pues, el apoyo de reconocidos intelectuales del continente a la invasión francesa contra México, por ser aquella nación portadora de la civilización contra la barbarie.

5.-Si bien muchos países del continente americano adolecen de escisiones en la conciencia jurídica y política esta situación es particularmente grave en el argentino por el hecho de haber recibido influencias de distintos referentes culturales que no han sido asimiladas. El problema grave radica, en 
última instancia, en la pretensión de salvar etapas históricas Somos los argentinos tributarios, en cierta medida, de la Edad Moderna bajo la cual nació, de un país que acusaba acentuado espíritu medieval pero con la inserción de un proyecto del liberalismo moderno y contemporáneo, para forjar "el país de los argentinos". Argentina, ha expresado Ciuro Caldani, ha continuado recibiendo aportes vinculados con los dos períodos, pero no tiene aún - como los demás países de América- la profundidad necesaria para desarrollar un presente y un futuro con sentido total y propio. Los pueblos que no han atravesado la Edad Antigua o la Edad Media tienen grandes dificultades para comprender en profundidad la Edad Moderna o la Edad Contemporánea ${ }^{14}$.

Ello comporta, en gran medida, la producción de obstáculos para desarrollar y alcanzar una cultura profundamente "humana" y en cambio se nos ofrece como resultante de aquella situación la formación de dos tipos de cultura, la comunitarista y la individualista. La primera denominación que no encapsula necesariamente a todos los miembros del sector con sentido comunitario, se entiende porque en su marco se comprende el desarrollo de vivir como una empresa de conjunto, en el individualismo se considera la vida de cada hombre como la manifestación de un fenómeno más particular.

Las raíces de la concepción comunitarista se dan de manera especial en la Edad Media, época en la que los protagonistas de la historia eran la Iglesia y el Estado. Claro que, hasta el siglo XX la evolución de los tiempos nos indica que sus manifestaciones fueron de raigambre hispanista y con una valoración hacia el pasado, en tanto que el del siglo XX, se dirige con marcada hostilidad hacia los elementos anglosajones y franceses orientando su mirada más hacia la consideración del presente.

En tanto que la individualista se nutre en la Edad Moderna época en la que se valoró al hombre como sujeto de la historia. Dentro de esta misma concepción podemos encontrar sectores más vinculados con aquella Edad o con la Contemporánea, sin comportar ambas oposiciones culturales. Es necesario señalar, que las tensiones emergentes de estos estilos provocan en el ambiente argentino, en muchos casos, situaciones que atentan contra la justicia y la convivencia al considerarse cada una de ellas como excluyente ${ }^{15}$. En el arco del proceso histórico argentino se pueden apreciar las etapas de dominación de una o de otra concepción ideológica. La comunitarista es evidente en el período de los Austrias y se afianzó en el marco de los terratenientes primitivos, los caudillos y los gauchos que sufre su primer ruptura bajo el gobierno liberal de Urquiza (1852-1862), para retomar su protagonismo con la incorporación del proletariado —en relevante proporción de origen inmigratorio del meridión italiano y español - la erección del gobierno populis- 
ta de Hipólito Yrigoyen (1916-1922 y 1928-1930) y del régimen peronista (1946-1955 y 1973-1976). La concepción individualista, con mayor anclaje en la monarquía borbónica, tiende a nuclear a la burguesía tradicional -especialmente a la "porteña" 16 , y nuevos burgueses e intelectuales influidos acentuadamente por las culturas francesa e inglesa se evidencia desde la Revolución de Mayo (1810), los postulados de la Generación de 1837, desde la victoria del general Justo José de Urquiza contra Rosas (1850) prolongándose hasta 1916. Con diversos altibajos se sucede en el gobierno desde 1930 al '46 para retomar la dirección política y cultural desde 1955 a 1973.

6.-La escisión a la que aludíamos tuvieron y tienen, si bien con ciertas connotaciones nuevas, su incidencia en el ámbito de la universidad. La carga negativa que padeció en gran medida la exacta comprensión de la herencia hispánica en la valoración objetiva de su accionar fue recogida en una historiografía cuyos responsables provenían del sector angloafrancesado imprimiendo con ello una especial tendencia a construir la historia con un maniqueísmo donde alternaban santos y demonios. Luego, la formación de la historia argentina se realizó al hilo de las alternancias en el poder de ambas concepciones, siendo decididamente más exitosa o al menos mejor difundida - quizás por asimilársela al sector de las élites intelectuales- la que olvidaba o mejor soslayaba el pasado, en la consideración de nuestra temporalidad.

La inútil fragmentación de nuestra historia pasó a las universidades y se verifica, según los protagonistas del poder, los discursos de tono siempre excluyentes respecto del sector que se quiere deprimir, marginar u hostilizar. Así, bajo la conducción de estilo comunitarista, paternalista, hay una revitalización de lo tradicional, su música, su literatura, de los símbolos patrios, la figura de Rosas, Yrigoyen o Perón y se critica indiscriminadamente la labor de Alberdi, Rivadavia, o Sarmiento cuyas estatuas sufren las depredaciones de los exaltados, que serán reivindicadas por el sector de fieles a esas figuras, y escarnecidas las defendidas por el sector que los han precedido en el poder. Como hemos expresado al comienzo, la fragmentación producida por las dos posturas llega a la utilización del autoritarismo en ambas, aunque se arrogan simultáneamente ser apóstoles de la democracia universitaria.

7.-Luego de la caída del gobierno peronista en 1955 y hasta el 1966 en la que se inicia el trágico período del general Juan Carlos Onganía, los objetivos declarados eran lograr la restauración reformista, la autonomía en los claustros y la libertad de cátedra. La verdaderos móviles: desperonizar la institución como lo habían intentado por decreto hacerlo con el país. Los políticos y universitarios antiperonistas, liberales, comunistas, radicales, socialistas y democristianos fueron los promotores de esta etapa. Se otorgó 
más impulso a los centros de investigación, se acordó mayor presupuesto para las Casas de Altos Estudios, se produjo la cesantía de profesores peronistas y neoperonistas. Se procedió pues a una tarea de total depuración - no ajena a la vida universitaria - de los docentes que hubiesen simpatizado con el régimen depuesto, a cargo de la denominada "Revolución Libertadora" 17.

Una nueva etapa iniciada por el general Onganía y denominada "revolución argentina", (1966-1973) se apropiará de la universidad con la aquiescencia del sector de tecnócratas desarrollistas, nacionalistas católicos y militares. Las razones alegadas serán la de reconstituir el "ser nacional" y la formación humanistica, en tanto que las verdaderas motivaciones eran la de erradicar el marxismo y el izquierdismo de la institución y cualquier manifestación política en sus claustros. Se aplicó el recurso de las intervenciones y se renovaron las expulsiones del personal académico. La respuesta fue la renuncia de profesores y la emigración de docentes y de investigadores hacia el exterior. En fin, la educación obedeció a los principios de la doctrina o ideología de la Seguridad Nacional alentada por los norteamericanos para toda América Latina.

Durante el período constitucional peronista (1973-1976) la universidad protagonizó un rol sumamente confuso. Se tomó la institución como pivote para lograr la hegemonía del Estado. A pesar de la brevedad de esta etapa emergerán dos tendencias antagónicas que dieron lugar a resistencias, luchas, y una gran alteración de la vida académica junto al terrorismo de izquierda y de derecha. Los propósitos declarados serían los de la "reconstrucción universitaria" ("73-'74) y "del restablecimiento del orden" ('74-'76). Sin embargo, se instrumentalizó la institución universitaria y se la arrastró en pos de un sistema político radicalizado y en crisis. El resultado nefasto fue la entronización de siete años de terror en el que se conculcaron los derechos humanos merced a un aparato represivo que cobraba víctimas en todos los sectores. Y la universidad argentina abonará la larga lista de desaparecidos.

Los cursos y recursos en la evolución universitaria, referida de modo sucinto, nos mueve a reflexionar acerca del desencuentro y la división de esta institución con la sociedad y consigo misma. Hoy, parece que Argentina va llegando a la "hora de la verdad" y por encima de aquél enfrentamiento entre los sectores "hispánico tradicional" y "angloafrancesado" va quedando diferenciado un sector más "liberal" y otro más "socialdemócrata". El primero estará compuesto por quienes estén conformes con la economía de mercado -aún en constitución-, los segundos por los que intenten corregir dichos resultados. Aunque todavía resulta demasiado prematuro hablar de la corrección de algo que no está configurado, y cabe señalar que la economía de mercado no surge en Argentina de un reclamo de sus bases sociales sino de una 
propuesta de sus gobernantes. Por otra parte, la asimilación del paradigma social demócrata, que corresponde a procesos de distribución de cierto modo "post- capitalistas" es distinto de la realidad que nos toca vivir, que es en mucho "pre-capitalista" 18 .

Creemos que es la universidad la institución más adecuada para luchar contra las fuerzas disgregadoras, la fatalidad y la inercia, porque ella es fundamentalmente un centro de actividad crítica y creadora para la autorealización humana por el uso de la inteligencia. Tine como misión fundamental la formación integral del ser humano y la defensa de su dignidad y no sólo la formación de profesionales ". Una de las tensiones más peligrosas a las que ha asistido - y asiste- la universidad argentina se refiere a la relación del "saber-poder" ${ }^{20}$. Es necesario revitalizar el concepto del saber como intrínsecamente valioso y no sirviendo a fines que alimentan luchas sectoriales y mezquinas, colaborando en el drama de tragedia que está conmocionando la universidad argentina.

Claro es que la específica composición de la realidad de Argentina, en la que subyacen ocultos muchos problemas fundamentales, ha limitado $y$ limita las posibilidades de diálogo y de consenso de los gobiernos arrastrando el quehacer universitario. Es necesario, realizar el mayor esfuerzo por hallar denominadores comunes superadores de la antinomia para posibilitar las vías de un profundo diálogo entre los argentinos. El éxito no podemos aún predecirlo, se halla en la incógnita del porvenir.

\section{NOTAS}

1 Es de destacar que las ideas hispánicas tenfan general acogimiento en el ámbito de las universidades de Chuquisaca (o Charcas) y la de Córdoba donde se formaron los eclesiásticos y los abogados. La doctrina de la colación mediata del poder la hallamos en Suárez en la cual está latente cierta base contractual o pactista vinculando al gobernante con la comunidad y por ello, se distancia en mucho al contrato social de Rousseau que tiene como intervinientes sólo a los individuos. La reasunción del poder a la comunidad para erigir sus propios órganos de gobierno obedece, en gran medida a la influencia hispánica. "El desplazamiento y la aplicación de estas ideologias hispánicas en el Río de la Plata, pese a la controversia de nuestros historiadores, se acusan con perfiles definidos", BIDART CAMPOS, Germán Historia polltica y constitucional argentina, t..I., Buenos Aires, Ediar, 1976, pag.27. Ver: SIERRA, Vicente, Historia de la Argentina, t. II, Bunos Aires, UTHEA, 1965, DE GANDIA, Enrique Historia de las ideas poltticas en la Argentina, t.V, Buenos Aires, Depalma, 1965, LEVENE, Ricardo Historia de las ideas sociales en Argentina, Buenos Aires-México, F.C.E., 1947, HALPHERIN DONGHI, Tulio Tradición poltitica española e ideologia revolucionaria de Mayo, Buenos Aires, Eudeba, 1961, entre otros..

"Los hombres de la Universidad de Buenos Aires como Juan Crisóstomo Lafinur, Juan Manuel Fernández Agüero, Pedro Somellera, Diego Alcorta introdujeron y encauzaron desde la cátedra la corriente filosófica del ideologismo con Destutt de Tracy, Condillac y otros, que hizo abortar la tentativa de restauración del viejo y caduco escolasticismo caracteristico de la universidad colo- 
nial", GONZALEZ, Julio V.Principios y fundamentos de La Reforma Universitaria, Santa Fe, Universidad Nacional del Litoral, 1930, pág. 11.

3 A partir de la universidad de Santo Domingo, creada en 1538, hasta el 1791 se cuentan 12 instituciones surgidas en la América española. En su enseñanza predominó el espíriu religioso conducido por las distintas órdenes que se asentaron en el territorio, destacándose de modo especial la de los jesuitas. "Su dsemperio ha sido severamente criticado por algunos historiadores quienes, olvidando las condiciones especiales en que esas universidades se desarrollaron, las consideran como atrasadas, tendenciosas y de acción perjudicial para el desatrollo americano", Ver: Sintesis Histórica de las Universidades argentinas, Publicación oficial de la Universidad de La Plata, 1939, pág. xxxi. También: RUBIO, David, La Universidad de San Marcos durante la colonización espanola, Madrid, Erial, 1935.

4 A las universidades de Córdoba y Buenos Aires debemos sumar tres, inicialmente provinciales y nacionalizadas tiempo después: la del Litoral creada en aquél carácter en 1889 , de La Plata en 1890 y Tucumán en 1912. Se nacionalizaron, respectivamente, en 1919, 1905 y 1920.

5 CIRIA, A y SANGUINETI H, La Reforma Universitaria, 1918-1983, t.I, Buenos Aires, Cedal, 1983, pág.23. Para un análisis profundo del tema ver: DEL MAZZO, Gabriel El movimieno de la reforma universitaria en la América Latina, Resistencia, Univ, del Nordeste, 1958, DANA MONTAÑO, Salvador M., La crisis argentina y la educación común y superior, Buenos Aires, Emecé, 1963.

6 La marcha ascendente de la Reforma tuvo su primera quiebra cuando Marcelo T. de Alvear sucedió en 1922 a Hipólito Yrigoyen en la presidencia de la Nación. Ambos perteneclan al Partido radical de raigambre populista pero muy pronto el nuevo presidente se distanció de sus principios y se adhirió a los conservadores. El primer ataque lo orientó hacia los claustros universitarios apelando al recurso de las intervenciones ejemplarizantes " $Y$ por primera vez -luego se repetirá exactamente el mismo fenómeno en 1930, 1945, 1958, 1966, y 1976 (fechas de golpes militares)muchos reformistas son excluídos del cuerpo docente y otros se alían con los profetas "del orden". Ver: CIRIA - SANGUINETTI, cit. También: LATTUCA, Ada Historia de la Universidad del Litorah Tesis doctoral, CIUNR, 1986.

7 PORTANTIERO, Juan C. Estudiantes y politica en la América Latina. El proceso de la Reforma Univeristaria, México, Siglo XXI, 1978.

8 El resultado de la Evaluación Diagnóstica aplicada a 2.450 ingresantes en el Curso Introductorio irrestricto de la Facultad de Derecho de la U.N. Rosario, afio 1995, sobre temas de historia argentina arrojó un $10 \%$ de aprobados. Acerca de la historia colonial el porcentaje fue aún más bajo.

9 En cuanto a los intentos "forzados" por modificar la realidad podemos decir que los argentinos receptaron para la elaboración de sus normas constitutivas el modelo constitucional norteamericano de carácter demoliberal y pensaron trasplantar una constitución cultural acorde al modelo inglés o francés con la importación de inmigrantes de aquellas regiones. Sin embargo. la realidad frustró las bases del proyecto al producirse el "aluvión inmigratorio" de espanoles e italianos con fuerte tradición paternalista y autoritaria. No obstante el Código Civil argentino (1870), es francés y su consecuencia fue, al año de su sanción, la trágica respuesta del "Martín Fierro" que lloraba la tierra perdida.

10 PEREZ LINDO, Augusto, Universidad, Polttica, Sociedad, Buenos Aires, Eudeba, 1985, pág. 86. IMAZ, José Luis de, Los que Mandan, 5ta.ed., Bunos Aires, Eudeba, 1966.

11 ALBERDI, Juan B.,El gobierno de Sud-América, segrín las miras de su revolución fundamentah Buenos Aires, Imp. Europea, 1866. Sobre el tema de la importación a ultranza de la "civilización moderna" en América Latina puede verse: MARTI, José, Nuestra América, Buenos Aires, Losada, 1980, ROIG, Arturo A., Teorla y critica del pensamiento latinoamericano, México, Tierra Firme, 1981. ZEA, Leopoldo Filosofia de la bistoria americana, Ira. reimp., México, Fondo de Cultura Económica, (en especial lo relativo a las características de los diversos proyectos), $\mathrm{KUSCH}$, 
Rodolfo, América Profunda, 3ra. ed., Buenos Aires, Bonum, 1986, CHEVALIER, François, América Latina de la independencia a nuestros dias, trad. Marfa L. Rieu, Barcelona, Labor, 1979, CIURO CALDANI, Miguel Angel, Nota sobre Hispanoamerica y la asunción del pensamiento juspublicista europeo, en "Investigación y Docencia", n०6, public. del Centro de Investigaciones de Filosofia Jurfdica y Filosofia Social de la Facultad de Derecho, U.N.R., Rosario, FIJ, 1987.

ROIG, Arturo A. Teorla....,cit., pág. 63. Sarmiento, autor de Civilización y Barbarie, solía jactarse: "yo he habituado los oídos de los americanos a oírse llamar bárbaros y ya no lo extranan". Ver: SARMIENTO, Domingo F., Campaña en el Ejercito Grande de Sudamerica (1854), México, FCE, 1958.

13 MIRO QUESADA, Francisco Antologia de la filosofia americana, México, Unam, 1968.

CIURO CALDANI, Miguel Angel, La escisión de la conciencia jurldica y politica argentina en Revista de la Universidad de Buenos Aires, Publicación dispuesta en homenaje al profesor Rafael Bielsa, Buenos Aires, 1983, vol. VI, pág. 22. También del autor: Notas para la comprensión jussflosofica de Amtrica Latina, "Boletín del Centro de Investigaciones de Filosofla Juridica y Filosofla Social", Facultad de Derecho, U.N.R., n 12, 1989.

15 "Aunque las dos concepciones tienen desarrollos significamente coherentes, el control del poder que han ejercido habitualmente los miembros del sector individualista y el carácter marginal que frecuentemente ha tenido el comunitarismoi; la influencia de ideas extrañas -por ejemplo, la penetración del fascismo en el comunitarismo o la proyección del positivismo en el individualismo- y los movimientos migratorios -principalemnete la inmigración hispánica e itálica, que revitalizó sobre todo la cultura comunitarista- han introducido variantes relativamente significativas en la composición ideológica y social de cada individuo", CIURO CALDANI, Miguel Angel , La escisión...cit, pág. 25.

16 Es sabido que desde la creación del Virreinato del Río de La Plata (1776) Bunos Aires aglutina el poder de la Nación, y provee en gran medida por importación, los criterios de conducción que no siempre cuentan con el consensio del resto del país. Asimismo, fuerza es reconocer que continúa siendo un foco atractivo como difusor de cultura -criticado pero a veces secretamente admirado por el resto del pais- y a través de su centro comercial se detecta el núcleo del sector juridico "angloafrancesado" con influencias definidas en la orientación del pals. Ver: CIURO CALDANI, Miguel Angel Aportes para la comprensión geojuridica interna de Argentina en Geojuridicidad en "Investigación y Docencia"...cit., n²2, 1994. págs., 33 a 36.

17 La exclusión de cualquier vestigio que recordara al "tirano depuesto", simbolos, libros, etc. fueron destruidos. La exclusión ideológica de ese movimiento mayoritario en las clases populares fue total. "Aquí podemos ver la distancia que media entre los objetivos declarados (democratización, liberalización, tolerancia) y los objetivos reales. Este desajuste entre la ideología y la práctica era el indice de un desencuentro fatal entre lis diferentes sectores sociales y políticos de la sociedad". PEREZ LINDO, Augusto Universidad, Politica y Sociedad...cit, pág. 130.

18 CIURO CALDANI, Miguel Angel, Argentina y sus posibilidades actuales de recepción del modelo capitalista, en "Boletín...cit, n $15,1992$.

19 Sobre la misión de la Universidad pude consultarse además de los clasicos en la materia: RAMIREZ, Roberto, La Universidad y los valores permanentes del bombre, en temas de pedagogia universitaria, Univ. Nac. del Litoral, Santa Fe, 1962; TAQUINI, Alberto, ¿Cumple la Universidad sus fines?, en idem, 1964.; RIVAROLA, Rodolfo, El problema universitario argentino en Problemas universitarios, Santa Fe, Colmegna, 1945.

20 Esta vertiente ha tenido como defensores a hombres ilustres tales como BACON, Francis cuando expresaba "la ciencia del hombre es la medida de su potencia". del autor: puede verse, Novum Organum, trad. de Cristóbal Letrán, Madrid, Sarpe, 1984. 